\title{
Stereological and morphological analysis of the effects of aging on spermatogenesis in rat testis ${ }^{1}$
}

\author{
Eduardo Pereira de Miranda', Fernando Lorenzini", Bruno Vinicius Duarte Neves'I', Eduardo Felippe \\ Melchioretto"I', Thiago Hota"', Rogerio De Fragalv
}

'Fellow Master degree, Postgraduate Program in Surgical Clinic, Department of Urology, Universidade Federal do Paraná (UFPR), Curitiba-PR, Brazil. Scientific, intellectual, conception and design of the study; acquisition, analysis and interpretation of data; technical procedures; histopathological examinations; statistical analysis; manuscript preparation; critical revision.

"PhD, Department of Urology, School of Medicine, UFPR, Curitiba-PR, Brazil. Scientific, intellectual, conception and design of the study; critical revision.

I'MD, Department of Urology, UFPR, Curitiba-PR, Brazil. Acquisition of data, technical procedures, histopathological examinations, critical revision.

IVPhD, Associate Professor, Department of Urology, School of Medicine, UFPR, Curitiba-PR, Brazil. Scientific, intellectual, conception and design of the study; analysis and interpretation of data; statistical analysis; critical revision.

\begin{abstract}
Purpose: To quantify, through stereological and morphometric analysis, spermatogenesis in rats undergoing the natural aging process.

Methods: Seventy-two male Wistar rats were divided into 6 equal groups according to age at the time of killing: $3,6,9,12,18$, and 24 months. All the rats were subjected orchiectomy and collection of testicular parenchymal fragments for histological and morphometric analysis. The numerical density of spermatids was calculated using a stereological study, and morphometric analysis was conducted to measure the height of the germinal epithelium and the area of the seminiferous tubules.

Results: We found that the 18 and 24 months groups showed a significant reduction in the number of round spermatids. However, the height of the germinal epithelium was not significantly different between the groups. The area of seminiferous tubules was also significantly reduced in the elderly rats compared to that in the young ones.

Conclusion: Aging of rats showed a significant reduction in the number of round spermatids and the area of the seminiferous tubules, more pronounced in the rats at 18 and 24 months of life.
\end{abstract}

Key words: Aging. Spermatogenesis. Infertility. Testis. Spermatids. Rats. 


\section{Introduction}

The human population has experienced a sustained increase in life span, especially in recent decades; this increase occurred first in developed countries and, subsequently, in developing countries. Professional and cultural factors and the use of modern contraceptive methods have also led to an increase in the age of paternity. Moreover, the use of assisted reproduction techniques has increased, and changes due to aging have become more evident and important as one of the factors for determining the fertility of couples in such cases $^{1}$.

Aging is a natural ongoing process characterized by morphological and structural degeneration, and like other organs, the gonads also deteriorate due to this process; however, unlike women, who present clinical signs of ovarian failure, men do not show accurate visibly signs of testicular failure ${ }^{2}$. Although spermatogenesis continues throughout life, the quantity and quality of this process in elderly men is lower than that in young men $^{2-4}$; however, it is difficult to determine the exact moment when this decline becomes more pronounced.

Besides spermatogenesis, another important role played by the testes is in the production of the male hormone, testosterone. Since all testicular functions are related to each other, infertile men have an increased risk of hypogonadism ${ }^{5}$. Aging affects both these testicular functions ${ }^{6}$. The aged male gonad presents structural and morphological changes such as decreased volume and reduced number of germ cells ${ }^{4}$, which are associated with a decrease in the quality of sperm and fertility ${ }^{7}$. The decrease in semen quality in elderly men may result, in addition to infertility, in an increase in the possibility of complications during pregnancy and certain diseases such as autism, schizophrenia, bipolarity, and achondroplasia ${ }^{8}$.
Stereology is the quantitative assessment of the three-dimensional structure and spatial arrangement of thin twodimensional sections of biological specimens ${ }^{9}$. This technique has been used in previous studies to evaluate parameters of the seminiferous tubule and germ cells ${ }^{9-11}$. In the present study, we conducted stereological analysis to precisely determine the stage of life when a greater deterioration in the morphological, cellular, and structural elements of spermatogenesis occurs with aging in rats.

\section{Methods}

The study was approved by the Ethics Committee in Animal Experimentation (CEEA), Department of Biological Sciences, Universidade Federal do Paraná. All animal experiments were conducted in accordance with the ethical principles established by the Brazilian College of Animal Experimentation (COBEA) and the requirements laid down in the "Guide for the Care and Use of Experimental Animals".

Seventy-two 3-months-old male albino Wistar rats (Rattus novergicus albinus, Rodentia, Mammalia) were used in this study. The rats were housed under a controlled temperature of $22^{\circ} \mathrm{C}$ with a light/dark cycle of $12 \mathrm{~h}$ and with controlled air moisture in an environment free from external noises. Filtered water and species-specific rations were supplied ad libitum throughout the experiment.

The animals were divided into six groups ( $n=12$ in each group) and killed at different ages: 3 months, 6 months, 9 months, 12 months, 18 months, and 24 months.

The animals were anesthetized with ketamine $(57.67 \mathrm{mg} / \mathrm{kg}$ ) and xylazine hydrochloride $(10 \mathrm{mg} / \mathrm{kg})$ via intraperitoneal injection under aseptic conditions. The procedures consisted of laparotomy and median thoracotomy for removal of organs 
(for use in other studies), cardiac incision with induction of cardiac arrest by exsanguination, and bilateral orchiectomy by a median scrotal incision, isolation, ligature, and sectioning of the spermatic cord, and resection of both testes. The left testes were immediately frozen at $-80^{\circ} \mathrm{C}$ (for use in another study), and the right testes of all the animals were weighed and measured (length, width, and thickness) and used in the present study.

\section{Morphometric and stereological analysis}

A single 2-mm (breadth and depth) incision was made in the upper, middle, and lower thirds of the right testes for better penetration of the fixative, and the testes were then submerged in ALFAC (alcohol $80 \%$, formaldehyde, and acetic acid) for 16 h. The testes were then transferred into $70 \%$ alcohol, followed by dehydration in a series of decreasing concentrations of xylene and alcohol for subsequent embedding in paraffin blocks.

The testes were then cut into $5-\mu \mathrm{m}$ thick sections using a microtome (American Optical, Spencer AO 820). To obtain random and uniformly isotropic sections, the Orientatior ${ }^{12}$ method was used, and the Physical Disector ${ }^{13}$ method was used to calculate the numerical density of the spermatids. The sampling of testicular tissue was performed with two consecutive sections excluding, among them, three $5-\mu \mathrm{m}$ sections, representing a thickness of $25 \mu \mathrm{m}$ between the planes for the determination of tri-dimensional quantitative parameters of spermatids from two-dimensional sections.

Subsequently, the histological slides were mounted with 3 sections of each sampling with hematoxylin \& eosin (HE) staining.

The assessment of the height of the germinal epithelium and calculation of the area of the seminiferous tubule was performed with the aid of an appropriate software (TsVieW).

Ten microscopic fields were chosen in each of the three histological sections to perform the analysis, which yielded a total of 360 fields in each group of rats.

The numerical density of the round spermatids (Nv[spermatids]), expressed as number of round spermatids per $\mu \mathrm{m}^{3}$ of testicular parenchyma, was calculated using the following formula:

$$
\begin{aligned}
& \mathrm{Nv}\left[\text { spermatid] }=\Sigma \mathrm{Q}_{\mathrm{A} \text { [spermatid] }}^{-} / \mathrm{Vol}[\text { disector] }\right. \\
& \text { In which: } \\
& \mathbf{\Sigma Q}_{\mathrm{A} \text { [spermatid] }}^{-}=\text {number of spermatids } \\
& \mathrm{Vol}_{\text {[disector] }}=\mathbf{e} . \text { At } \\
& \mathrm{e}=\text { thickness of the micrometer } \\
& \mathrm{At}=\text { test area of the upper plane }
\end{aligned}
$$

\section{Statistical analysis}

Statistical analysis was performed by analysis of variance (ANOVA) and by using posthoc Tukey's honest significant difference (HSD). Parameters for each group were compared using a statistical significance threshold of less than 5\% $(P<0.05)$. Pearson (parametric) and Spearman (nonparametric) correlations were used to correlate numerical variables.

\section{- Results}

None of the animals in the study died before they were killed, and the animals in older-age groups presented characteristics of aging, such as thinning of hair and hypoactivity.

\section{Stereological analysis}

The numerical density of round 
spermatids was slightly lower in the 6 months group than in the 3 months group. The 9 and 12 months groups showed slightly higher numerical density of round spermatids than the 3 and 6 months groups. In the 18 and 24 months groups, the numerical density of round spermatids was significantly reduced $(P<0.0001$; Figure 1, and Tables 1 and 2$)$. Figure 2 shows a sample of the photodocumentation of the testicular parenchyma.

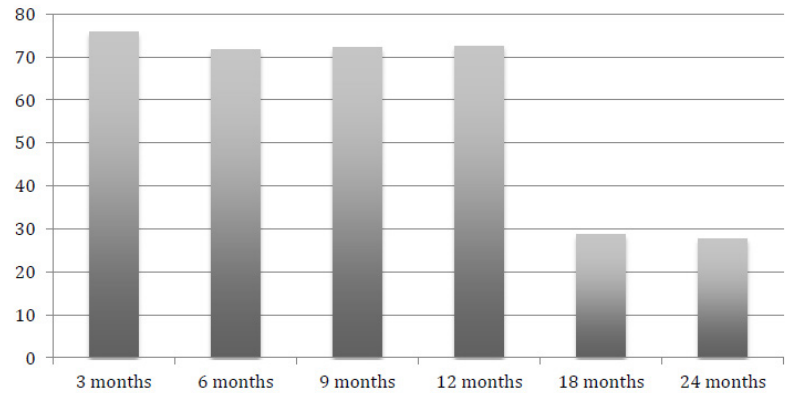

Figure 1 - Means of the numerical densities of round spermatids (number of spermatids $/ \mu \mathrm{m}^{3}$ ).

Table 1 - Average of the numerical densities of round spermatids in the different groups.

\begin{tabular}{llllc}
\hline Groups & N & Mean & SD & 95\% Cl \\
\hline 3 months & 360 & 75.74 & 15.96 & $74.08-77.39$ \\
6 months & 360 & 71.75 & 17.77 & $69.91-73.59$ \\
9 months & 360 & 72.13 & 17.63 & $70.30-73.95$ \\
12 months & 360 & 72.60 & 17.37 & $70.79-74.39$ \\
18 months & 360 & $28.64^{*}$ & 1.67 & $28.46-28.81$ \\
24 months & 360 & $27.89^{*}$ & 6.17 & $27.24-28.52$ \\
\hline
\end{tabular}

$* P<0.001$ (ANOVA)

Note: $n=$ number of microscopic fields analyzed; Mean = mean of the numerical densities of round spermatids (number of round spermatids; $\mathrm{SD}=$ standard deviation; $\mathrm{Cl}=$ confidence interval).

Table 2 - Comparison between the mean numerical densities of round spermatids of rats in different groups.

\begin{tabular}{ccccc} 
Group & $\begin{array}{c}\text { Comparison } \\
\text { Groups }\end{array}$ & $\begin{array}{c}\text { Difference between mean numerical } \\
\text { densities of round spermatids }\end{array}$ & P value & $95 \%$ Cl \\
\hline 3 months & 6 months & 3.98 & $0.003^{*}$ & $0.94-7.01$ \\
& 9 months & 3.60 & $0.009^{*}$ & $0.57-6.64$ \\
& 12 months & 3.13 & $0.038^{*}$ & $0.10-6.17$ \\
6 months & 18 months & 47.09 & $0.000^{*}$ & $44.05-50.13$ \\
& 24 months & 47.88 & $0.000^{*}$ & $44.81-50.88$ \\
& 12 months & -0.37 & 0.999 & $-3.40-2.66$ \\
9 months & 18 months & -0.84 & 0.964 & $-3.87-2.19$ \\
& 24 months & 43.11 & $0.000^{*}$ & $40.07-46.15$ \\
& 12 months & 43.86 & $0.000^{*}$ & $40.83-46.90$ \\
12 months & 24 months & -0.46 & 0.998 & $-3.50-2.56$ \\
& 18 months & 43.48 & $0.000^{*}$ & $40.45-46.52$ \\
18 months & 24 months & 44.24 & $0.000^{*}$ & $41.20-47.27$ \\
\hline
\end{tabular}

$*$ P $<0.05$ (ANOVA - Tukey post hoc)

Note: the difference between the mean = difference between the mean numerical densities of round spermatids (number of round spermatids $/ \mu \mathrm{m}^{3}$ ) in different groups of rats; $\mathrm{Cl}=$ confidence interval. 


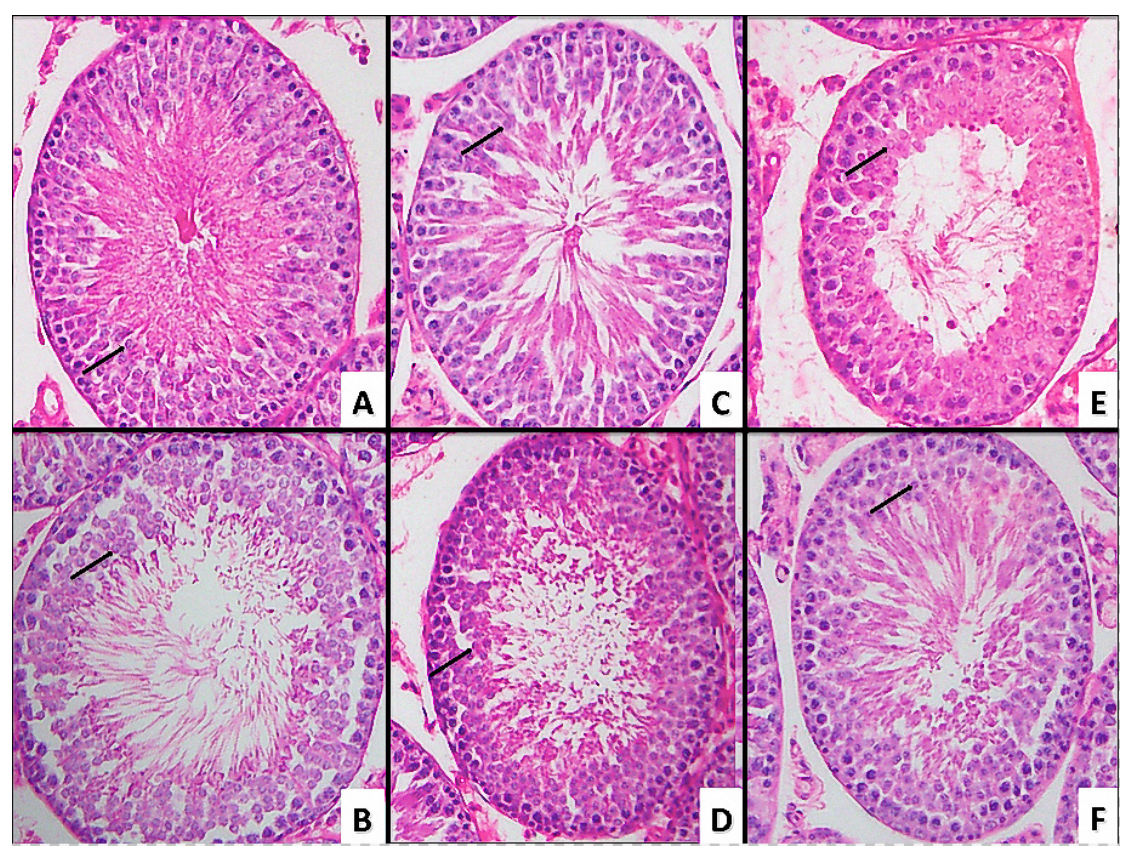

Figure 2 - Microscopic sample of testicular parenchyma of a rat from the (A) 3-months-old group, (B) 6-months-old group, (C) 9-months-old group, (D) 12-months-group, (E) 18-months-old group, (F) 24-monthsold group. Showing a decrease in the number of spermatids (black arrows: round espermatids).

\section{Morphometric analysis}

The results of the macroscopic morphometric analysis (weight, dimensions, and volume) were not significantly different between the groups.

The height of the germinal epithelium, as assessed by microscopic analysis, was significantly reduced in the 18 months group (mean=100.06 $\mu \mathrm{m}$ ) compared to that in the other groups. However, the 24 months group showed a significant increase (mean $=108.21$ $\mu \mathrm{m})$ compared to the 18 months group, with a similar value to that observed in the groups with younger rats (Figure 3, and Tables 3 and 4).

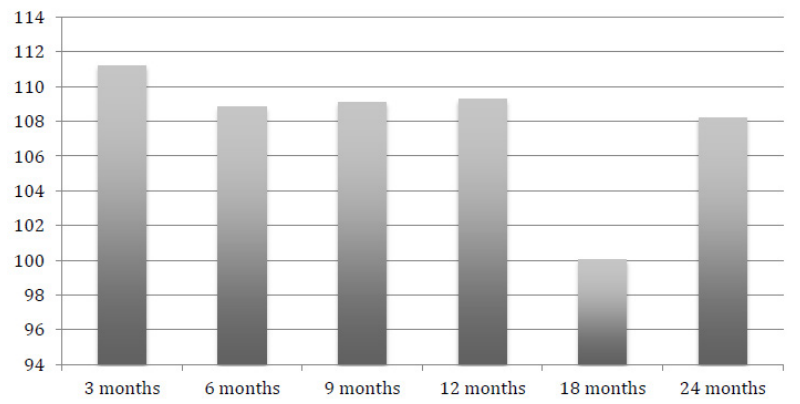

Figure 3 - Mean height of the germinal epithelium $(\mu \mathrm{m})$.

Table 3 - Mean height of the germinal epithelium of rats in the different groups.

\begin{tabular}{llccc}
\hline Groups & $\mathbf{n}$ & Mean height of the germinal epithelium $(\mu \mathrm{m})$ & $\mathbf{S D}$ & $\mathbf{9 5 \%} \mathbf{C l}$ \\
\hline 3 months & 360 & 111.23 & 20.66 & $109.09-113.37$ \\
6 months & 360 & 108.82 & 20.99 & $106.64-110.99$ \\
9 months & 360 & 109.12 & 20.79 & $106.96-111.27$ \\
12 months & 360 & 109.26 & 22.13 & $106.97-111.56$ \\
18 months & 360 & $100.06^{*}$ & 16.03 & $98.27-101.86$ \\
24 months & 360 & 108.21 & 12.92 & $106.87-109.55$ \\
\hline
\end{tabular}

$* \mathrm{P}<0.005$ (ANOVA)

Note: $\mathrm{n}=$ number of microscopic fields analyzed; Mean = mean height of the germinal epithelium; $\mathrm{SD}=$ standard deviation; $\mathrm{Cl}=$ confidence interval. 
Table 4 - Comparison between the mean heights of the germinal epithelium between the different groups.

\begin{tabular}{|c|c|c|c|c|}
\hline \multicolumn{2}{|c|}{ Comparison } & \multirow{2}{*}{$\begin{array}{l}\text { Difference between the mean heights } \\
\text { of the germinal epithelium ( } \mu \mathrm{m})\end{array}$} & \multirow[t]{2}{*}{$P$ value } & \multirow[t]{2}{*}{$95 \% \mathrm{Cl}$} \\
\hline Group & Groups & & & \\
\hline \multirow[t]{5}{*}{3 months } & 6 months & 2.41 & 0.545 & $-1.68-6.51$ \\
\hline & 9 months & 2.11 & 0.682 & $-1.98-6.21$ \\
\hline & 12 months & 1.97 & 0.744 & $-2.12-6.07$ \\
\hline & 18 months & 11.16 & $0.000^{*}$ & $6.90-15.43$ \\
\hline & 24 months & 3.02 & 0.285 & $-1.07-7.12$ \\
\hline \multirow[t]{4}{*}{6 months } & 9 months & -0.29 & 1.000 & $-4.39-3.80$ \\
\hline & 12 months & -0.44 & 1.000 & $-4.54-3.65$ \\
\hline & 18 months & 8.75 & $0.000^{*}$ & $4.48-13.01$ \\
\hline & 24 months & 0.60 & 0.998 & $-3.48-4.70$ \\
\hline \multirow[t]{3}{*}{9 months } & 12 months & -0.14 & 1.000 & $-4.24-3.95$ \\
\hline & 18 months & 9.05 & $0.000^{*}$ & $4.78-13.31$ \\
\hline & 24 months & 0.90 & 0.998 & $-3.19-5.00$ \\
\hline \multirow[t]{2}{*}{12 months } & 18 months & 9.19 & $0.000^{*}$ & 4.93-13.46 \\
\hline & 24 months & 1.05 & 0.978 & $-3.04-5.15$ \\
\hline 18 months & 24 months & -8.14 & $0.000^{*}$ & $-12.40--3.87$ \\
\hline
\end{tabular}

*P<0.05 (ANOVA - Tukey post hoc)

Note: Difference between the means = difference between the mean heights of the germinal epithelium in the different groups of rats; $\mathrm{Cl}=$ confidence interval.

With regard to the tubular area, the results were similar to those found in the stereological analysis of the numerical density of spermatids. The 18 and 24 months groups showed a significant decrease in tubular area (6726.21 $\mu^{2}$ and $7395.75 \mu \mathrm{m}^{2}$, respectively) compared to the other groups. However, unlike in the spermatids, the variation in the tubular area between the young and old rats was very slight (Figure 4, and Tables 5 and 6).

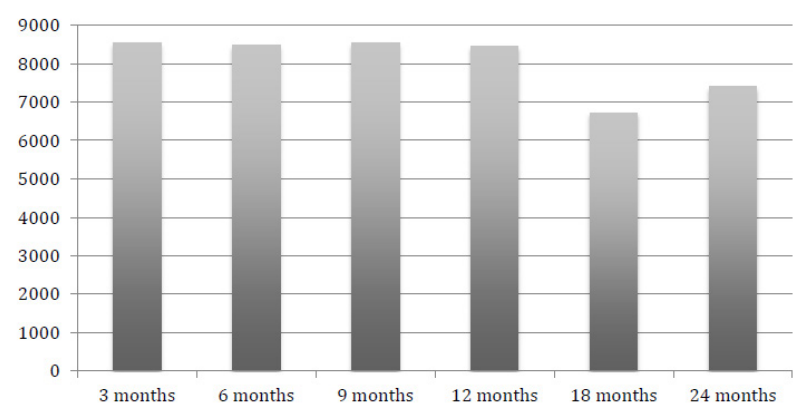

Figure 4 - Mean area of the seminiferous tubules $\left(\mu \mathrm{m}^{2}\right)$.

Table 5 - Mean tubular area in the different groups.

\begin{tabular}{lcccc}
\hline Groups & $\mathbf{n}$ & Mean $\left(\boldsymbol{\mu m}^{2}\right)$ & SD & $\mathbf{9 5 \% ~ C l}$ \\
\hline 3 months & 360 & 8540.59 & 723.42 & $8465.60-8615.57$ \\
6 months & 360 & 8475.71 & 711.42 & $8401.97-8549.45$ \\
9 months & 360 & 8533.54 & 688.97 & $8462.13-8604.95$ \\
12 months & 360 & 8457.50 & 731.20 & $8381.71-8533.29$ \\
18 months & 360 & $6726.21^{*}$ & 825.90 & $6640.61-6811.82$ \\
24 months & 360 & $7395.75^{*}$ & 707.39 & $7322.43-7469.07$ \\
\hline
\end{tabular}

$* p<0.005$

Note: $\mathrm{n}$ = number of microscopic fields analyzed; Mean = mean tubular area in the different groups of rats; $\mathrm{SD}=\mathrm{standard}$ deviation; $\mathrm{Cl}=$ a confidence interval. 
Table 6 - Comparison of the mean tubular areas between the different groups of rats.

\begin{tabular}{ccccc}
\multicolumn{2}{c}{ Comparison } & $\begin{array}{c}\text { Difference between mean } \\
\text { tubular areas }\left(\mu \mathrm{m}^{2}\right)\end{array}$ & P value & 95\% Cl \\
\hline 3 months & Groups & 64.87 & 0.843 & $-90.89-220.65$ \\
& 6 months & 7.04 & 1.000 & $-148.72-162.82$ \\
& 9 months & 83.08 & 0.650 & $-72.68-238.86$ \\
& 12 months & 1814.37 & $0.000^{*}$ & $1658.59-1970.14$ \\
6 months & 18 months & 1144.83 & $0.000^{*}$ & $989.06-1300.61$ \\
& 24 months & -57.82 & 0.898 & $-213.60-97.94$ \\
& 9 months & 18.20 & 0.999 & $-137.56-173.98$ \\
9 months & 12 months & 1749.49 & $0.000^{*}$ & $1593.72-1905.27$ \\
& 18 months & 1079.96 & $0.000^{*}$ & $924.18-1235.73$ \\
& 24 months & 76.03 & 0.732 & $-79.73-231.81$ \\
12 months & 18 months & 1807.32 & $0.000^{*}$ & $1651.54-1963.09$ \\
18 months & 24 months & 1137.78 & $0.000^{*}$ & $982.01-1293.56$ \\
& 18 months & 1731.28 & $0.000^{*}$ & $1575.51-1887.06$ \\
\hline
\end{tabular}

$* \mathrm{P}<0.05$ (ANOVA - Tukey post hoc)

Note: Difference between the mean = difference in the mean tubular areas between different groups of rats; $\mathrm{Cl}=\mathrm{confidence}$ interval.

\section{Discussion}

To better understanding the aging process and its characteristics, it is necessary to conduct studies with long follow-up times and using subjects at different stages of life, which requires experimental animal. Since rats have a short biological cycle, their entire life cycle can be controlled and the changes in spermatogenesis with the passage of time can be compared. The design of the groups in the present study allowed us to examine the animals at critical moments such as young adult (3 months of age) and at old age (24 months of age $)^{14}$.

With an increase in the average life span and with couples tending to postpone conception, knowledge of the events occurring during spermatogenesis in aged populations and the consequences of aging on spermatogenesis has become important for both treatment and counseling. In a review article, Kovac et al. previously showed that, in addition to low seminal quality and histological changes, paternal aging also leads to an increased risk of miscarriages, genetic abnormalities, cancer, autism, and other psychiatric disorders in the offspring ${ }^{1}$. Serre et $a .^{15}$ also found similar results in an animal study, which indicated an increase in the preimplantation loss of the embryo, decrease in fetal weight, and increase in neonatal death in offspring generated by elderly animals.

Spermatogenesis and male fertility have been extensively studied, and the factors that alter them, such as varicocele, torsion of the testis, and cryptorchidism, have already been the targets of numerous studies $^{16-18}$. As a variable that affects all beings, aging has been the focus of various studies, which have indicated testicular changes and change in seminal quality with increasing age ${ }^{4,11,19}$. However, most of these studies have only analyzed what occurs in older men or 
compared it to observations in young men without establishing a time point for when these changes occur. In the present study, we identified stability of the analyzed variables in the first four groups and a significant decrease in the same variables in the last two groups, which indicated that deterioration in spermatogenesis does not occur uniformly.

The results of the present study are also consistent with those of previous studies, which also revealed a regression in the quality of spermatogenesis and decrease in the number of germinal cells with age ${ }^{4,20}$. Our study showed that the histology with regard to spermatogenesis remains unchanged in the period between puberty and the initial two-thirds of life and that there is a marked decline in the last one-third stage of life, which indicates that fertility in a 3-months-old rat and a 12-months-old rat is probably the same. In men, it can be inferred that this decline occurs between the fourth and sixth decade of life ${ }^{14}$.

Cellular apoptosis is a component of normal spermatogenesis, and it maintains an appropriate number of germ cells and eliminates defective cells. An increase in apoptosis associated with a decrease in cell proliferation in aged testesleads to an imbalance and a consequent decrease in the number of germ cells ${ }^{21}$. The results of the present study show a reduction in the number of spermatids in aged testes, which is in agreement with previous literature that showed a decrease in the number of spermatids while the number of spermatogonia and spermatocytes remained stable when compared to that in young testes ${ }^{4,22}$. Furthermore, previously, Tomomasa et al. ${ }^{23}$ analyzed the spermatogenesis of cryptorchid rats and found an increase in spermatocyte apoptosis as a cause of germinal cell reduction. Thus, the increase in spermatocyte apoptosis probably explains the results obtained in the present study.

Spermatogenesis is a self-renewing productive system that is maintained by stem cells (spermatogonial stem cells), which continually renew and produce other germ cells and, a priori, maintain their quality and quantity throughout life ${ }^{24}$. In this study, we showed that a decrease in the number of spermatids occurs with aging. In a study involving the transplantation of stem cells from elderly rats into young mouse testes, Ryu et al. ${ }^{25}$ found that cells from the elderly rats in a young environment maintained spermatogenesis for another 3 years and concluded that the deterioration of spermatogenesis in elderly men is related to a deterioration of the testicular microenvironment.

Our results also indicate that, unlike spermatid counts, when the tubular area and height of the germinal epithelium were analyzed, there was either no difference or only a slight difference between the elderly rats and the young ones. In a previous study, Xia et al. ${ }^{11}$ analyzed the histopathology of the testes of men with advanced prostate cancer subjected to orchiectomy and compared them with the histopathologies of testicular biopsies of young men and found similar results; they therefore hypothesized connective tissue hyperplasia and interstitial laxity as an explanation for this finding.

One limitation of the present study is that we did not conduct seminal analysis. Nevertheless, we established, with follow-up time and stereological (three-dimensional) analysis, that the decrease in the number of spermatids and, consequently, the deterioration of spermatogenesis occurs in rats at 18 months of age. Further studies with more specific analyses aimed at determining the causes and consequences of this deterioration need to be conducted in the future.

\section{Conclusions}

The aging of the rats led to a deterioration of histological parameters of the spermatogenesis by a significant decrease in the 
number of round spermatids and a decrease in the area of the seminiferous tubules. Although, at the stage of life where there is the greater histological loss of the spermatogenesis there are no obvious clinical signs, this study showed that it occurs mainly at 18 months of age

\section{References}

1. Kovac JR, Addai J, Smith RP, Coward RM, Lamb DJ, Lipshultz LI. The effects of advanced paternal age on fertility. Asian J Androl. 2013 Nov;15(6):723-8. doi: 10.1038/aja.2013.92.

2. Eskenazi B, Wyrobek AJ, Sloter E, Kidd SA, Moore L, Young S, Moore D. The association of age and semen quality in healthy men. Hum Reprod. 2003 Feb;18(2):447-54. PMID: 12571189.

3. Plas $E$, Berger $P$, Hermann $M$, Pflüger $H$. Effects of aging on male fertility? Exp Gerontol. 2000 Aug;35(5):543-51. PMID: 10978677.

4. Jiang $H$, Zhu WJ, Li J, Chen QJ, Liang WB, Gu YQ. Quantitative histological analysis and ultrastructure of the aging human testis. Int Urol Nephrol. 2014 May;46(5):879-85. doi: 10.1007/s11255-013-0610-0.

5. O’Brien JH, Lazarou S, Deane L, Jarvi K, Zini A. Erectile dysfunction and andropause symptoms in infertile men. J Urol. 2005 Nov;174(5):1932-4. doi: 10.1097/01. ju.0000177453.14334.a2.

6. Beattie MC, Adekola L, Papadopoulos $\mathrm{V}$, Chen $\mathrm{H}$, Zirkin BR. Leydig cell aging and hypogonadism. Exp Gerontol. 2015 Aug;68:87-91. doi: 10.1016/j. exger.2015.02.014.

7. Hellstrom WJ, Overstreet JW, Sikka SC, Denne J, Ahuja S, Hoover AM, Sides GD, Cordell WH, Harrison LM, Whitaker JS. Semen and sperm reference ranges for men 45 years of age and older. J Androl. 2006 May-Jun;27(3):421-8. doi: 10.2164/ jandrol.05156.

8. Lawson G, Fletcher R. Delayed fatherhood. J Fam Plann Reprod Health Care. 2014 Oct;40(4):283-8. doi: 10.1136/ jfprhc-2013-100866.

9. Liu Z, Chang Q, Xu ZL, Zhang ZG. Stereological measurement of rat's seminiferous tubule. Chin Med J (Engl). 2009 Nov;122(21):26436. PMID: 19951585.
10.Bechara GR, de Souza DB, Simoes M, FelixPatrício B, Medeiros JL Jr, Costa WS, Sampaio FJ. Testicular morphology and spermatozoid parameters in spontaneously hypertensive rats treated with enalapril. J Urol. 2015 Nov;194(5):1498-503. doi: 10.1016/j. juro.2015.06.073.

11.Xia Y, Zhu WJ, Hao SF, Liang WB, Li J. Stereological analysis of age-related changes of testicular peritubular cells in men. Arch Gerontol Geriatr. 2012 Jul-Aug;55(1):116-9. doi: 10.1016/j.archger.2011.05.005.

12. Mattfeldt T, Mobius HJ, Mall G. Orthogonal triplet probes: an efficient method for unbiased estimation of length and surface of objects with unknown orientation in space. J Microsc. 1985 Sep;139(3):279-89. PMID: 3908688.

13. Sterio DC. The unbiased estimation of number and sizes of arbitrary particles using the disector. J Microsc. 1984 May;134(2):127-36. PMID: 6737468.

14.Quinn R. Comparing rat's to human's age: how old is my rat in people years? Nutrition. 2005 Jun;21(6):775-7. doi: 10.1016/j. nut.2005.04.002.

15.Serre V, Robaire B. Paternal age affects fertility and progeny outcome in the Brown Norway rat. Fertil Steril. 1998 Oct;70(4):62531. PMID: 9797088.

16.Al Bakri A, Lo K, Grober E, Cassidy D, Cardoso JP, Jarvi K. Time for improvement in semen parameters after varicocelectomy. J Urol. 2012 Jan;187(1):227-31. doi: 10.1016/j. juro.2011.09.041.

17.Lorenzini F, Tambara Filho R, Gomes RP, Martino-Andrade AJ, Erdmann TR, Matias JE. Long-term effects of the testicular torsion on the spermatogenesis of the contralateral testis and the preventive value of the twisted testis orchiepididymectomy. Acta Cir Bras. 2012 Jun;27(6):388-95. PMID: 22666756.

18.Penson DF, Lugg JA, Coyne C, Sadeghi F, Freedman AL, Gonzalez-Cadavid NF, Rajfer J. Effect of cryptorchidism on testicular histology in a naturally cryptorchid animal model. J Urol. 1997 Nov;158(5):1978-82. PMID: 9334653.

19.Well $D$, Yang $H$, Houseni $M$, Iruvuri $S$, Alzeair S, Sansovini M, Wintering N, Alavi A, Torigian DA. Age-related structural and metabolic changes in the pelvic 
reproductive end organs. Semin Nucl Med. 2007 May;37(3):173-84. doi: 10.1053/j. semnuclmed.2007.01.004.

20.Levy S, Serre V, Hermo L, Robaire B. The effects of aging on the seminiferous epithelium and the blood-testis barrier of the Brown Norway rat. J Androl. 1999 MayJun;20(3):356-65. PMID: 10386815.

21.Pastor LM, Zuasti A, Ferrer C, BernalMañas CM, Morales E, Beltrán-Frutos E, Seco-Rovira V. Proliferation and apoptosis in aged and photoregressed mammalian seminiferous epithelium, with particular attention to rodents and humans. Reprod Domest Anim. 2011 Feb;46(1):155-64. doi: 10.1111/j.1439-0531.2009.01573.x.

22.Kimura M, Itoh N, Takagi S, Sasao T, Takahashi A, Masumori N, Tsukamoto T. Balance of apoptosis and proliferation of germ cells related to spermatogenesis in aged men. J Androl. 2003 Mar-Apr;24(2):185-91. PMID: 12634304.

23.Tomomasa $H$, Adachi $Y$, Oshio S, Umeda T, Irie H, Ishikawa H. Germ cell apoptosis in undescended testis: the origin of its impaired spermatogenesis in the TS inbred rat. J Urol. 2002 Jul;168(1):343-7. PMID: 12050567.

24.Brinster RL. Germline stem cell transplantation and transgenesis. Science. 2002 Jun;296(5576):2174-6. doi: 10.1126/ science.1071607.

25. Ryu BY, Orwig KE, Oatley JM, Avarbock MR, Brinster RL. Effects of aging and niche microenvironment on spermatogonial stem cell self-renewal. Stem Cells. 2006 Jun;24(6):1505-11. doi: 10.1634/ stemcells.2005-0580.

\section{Correspondence:}

Eduardo Pereira de Miranda

Rua Juci Cidade, 121/501

88701-425 Tubarão - SC Brasil

Tel.: (55 48)99101-0656

eduardo.miranda1982@gmail.com

Received: June 09, 2018

Review: Aug 10, 2018

Accepted: Sept 12, 2018
Conflict of interest: none

Financial source: none

${ }^{1}$ Research performed at Laboratory of Anatomy and Experimental Surgery, Division of Urology, Department of Surgery, Universidade Federal do Paraná (UFPR), Curitiba-PR, Brazil. Part of Master degree thesis, Postgraduate Program in Surgical Clinic. Tutors: Rogério de Fraga and Fernando Lorenzini. 